\title{
PROVAS ILÍCITAS E SUA APLICAÇÃO PRO SOCIETATE NO PROCESSO PENAL BRASILEIRO
}

\author{
Lucas Whitaker Piai, Sérgio Mastellini \\ Universidade do Oeste Paulista - UNOESTE, Presidente Prudente, SP. E-mail: lucaspiai@hotmail.com
}

\section{RESUMO}

Trata o presente estudo da dinâmica atual da admissão ou não das provas ilícitas no processo penal pátrio, bem como suas correntes de utilização e implicações jurídicas de cada ponto de vista defendido pela doutrina, especialmente a aplicação pro societate. Com a evolução e consequente amadurecimento do Direito, houve uma relativização de normas antes tidas com um status de quase que absolutas, especialmente quando em jogo está direito fundamental do indivíduo. A doutrina divide-se, atualmente, em correntes de inadmissibilidade, admissibilidade somente a favor da defesa e, minoritariamente, admissibilidade também a favor da acusação, em nome de uma realização da justiça no caso concreto. Fazse presente, outrossim, a discussão acerca do aproveitamento das provas derivadas das ilícitas, ainda que obtidas de acordo com os ditames legais. A metodologia constou de diversas pesquisas bibliográficas, leituras, artigos eletrônicos, estudo da discussão do tema e legislação pertinente, capaz de dar fundamentação ao estudo. Conclui-se que a utilização de provas ilícitas é plausível, sobretudo pela defesa, podendo, inclusive, admitir-se o seu aproveitamento pro societate, em casos graves e excepcionais. Devese, contudo, contar com mecanismos que balizem o seu aproveitamento, em quaisquer casos, a fim de evitar a ocorrência de injustiças em nome da realização da justiça.

Palavras-chave: Direito Processual Penal. Provas llícitas. Pro Societate.

\section{ILLEGAL EVIDENCES AND PRO SOCIETATE APPLICATION THE BRAZILIAN CRIMINAL PROCEDURAL LAW}

\begin{abstract}
The present study is about the current dynamic of the admissibility or not of illegal evidence on the Brazilian procedural legislation, as well as its branches of application and the legal implications of each point of view advocated by legal literature, especially pro societate. As Law evolved and matured, there has been a relativization of rules previously held with a status of almost absolute, especially when a fundamental right of the person is on the line. The doctrine is currently divided into three branches: inadmissibility, admissibility by the defense and, in a much smaller scale, admissibility by the prosecution, aiming to concretely obtain justice. The discussion about the use of evidence derived from illicit evidence is present as well, even if produced under legal standards. The methodology consisted of several bibliographical researches, readings, electronic articles, study of the topic's discussion and pertinent legislation. Therefore, it is concluded that the use of illicit evidence is plausible, above all for the defense, and even its use may be admitted pro societate, in serious and exceptional cases. However, it is necessary to have mechanisms that guide its use, in any case, in order to avoid the occurrence of injustices in the name of justice.
\end{abstract}

Keywords: Criminal Procedural Law. Illegal Evidence. Pro Societate. 


\section{INTRODUÇÃO}

O Direito, como é conhecido hoje, é muito diferente do que foi sua versão primitiva. Inclusive, nos primórdios da sociedade humana, o Direito não era nem tido como uma ciência, dado que a resolução dos conflitos se dava pelo uso da força. Como o indivíduo mais forte se impunha, não havia necessidade para a figura da prova - as lides, àquela época, prescindiam de fundamentação nas discussões.

Com a inevitável evolução que se sucedeu em todos os campos de conhecimento humano, sugiram os primeiros embriões do que viriam a ser os mecanismos de prova. Como as sociedades rudimentares possuíam como alicerce a religião, havia uma concepção de origem divina do Direito. Portanto, as provas eram, também, essencialmente ligadas à religião, como as provas ordálias, juramentos e até combates judiciais.

Com maior racionalidade que se seguiu, ocorreu o fortalecimento do Estado e a consagração da sua interferência na resolução de conflitos entre os particulares. Assim, a arbitragem obrigatória, na figura da justiça pública, tornou-se a regra.

Neste contexto, surgiu também a necessidade de se comprovar os fatos alegados em uma demanda, e a produção de elementos probatórios que pudessem confirmar ou invalidar os fatos passou a ter, portanto, participação essencial nas discussões judiciais.

Ainda que as alterações sofridas pelo Direito sejam lentas e desproporcionais em relação à evolução da dinâmica social, a ciência jurídica passa por mudanças que acabam por alterar a interpretação e aplicação de normas, levando a resultados concretos diferentes.

$\mathrm{Na}$ esteira de uma cada vez maior tendência garantista, há uma crescente valorização dos direitos humanos e garantias fundamentais dos indivíduos, de maneira que o Estado é tido como responsável pela preservação destas premissas em seus atos, dentre eles a persecução penal.

Pelo fato de uma condenação à pena privativa de liberdade ser verdadeira restrição de garantia individual, verifica-se a necessidade de todo o iter processual penal utilizado para se obter esse fim ser pautado em rígidas regras, visando, justamente, a preservação dos direitos do réu.
Nesse âmbito está inserida a discussão acerca da admissibilidade ou não das provas ilícitas no processo penal, sendo essas vedadas pela Constituição Federal em seu artigo 5으, inciso LVI (BRASIL, 1988). Contudo, tal comando constitucional não deve ser interpretado de maneira isolada, rígida, e sim sistematicamente, em concordância com as demais normas presentes na Carta Magna, resultando, assim, em uma aplicação mais justa e realista da norma ao caso concreto.

Nesta senda, em um Estado dito democrático de Direito, objetiva-se o respeito e a concretização dos direitos dos cidadãos. Entretanto, como não há direito absoluto, haverá momentos em que direitos fundamentais protegidos entrarão em conflito, e será necessária a relativização de um em detrimento de outro, a fim de se alcançar a justiça concreta.

O dilema exemplificado se apresenta na utilização ou não das provas ilícitas no processo penal pátrio. Por meio de uma reflexão acerca do tema, infere-se que sua vedação constitucional e legal possui escopo de proteção ao indivíduo acusado criminalmente. Restringindo-se a produção de provas pelo Estado aos moldes legais, são evitados abusos cometidos durante a persecução penal, revestindo o processo de legalidade e legitimidade.

Por outro lado, descartar evidências consideradas ilícitas pode gerar consequências sérias que, dependendo do ponto de vista em que se analise a situação, podem implicar numa concreta injustiça.

Em casos onde o único jeito de o acusado comprovar sua inocência seja utilizando-se de uma prova ilícita, seria razoável que sejam estas vedadas, mesmo estando em jogo direito valiosíssimo como a liberdade? À vista disso, boa parte da doutrina admite a utilização de provas ilícitas somente quando favoráveis ao réu - pro reo -, em nome dos princípios da proporcionalidade e da razoabilidade.

Contrario sensu, significativa parcela dos estudiosos do Direito entende inadmissíveis as provas ilícitas e suas derivadas, independentemente de sua finalidade - pro reo ou pro societate - de modo que o devido processo legal seja respeitado. Se ilícitas são, não devem ser aproveitadas no processo penal, uma vez que revestidas pelo manto da ilegalidade. Obrigatório, pois, seu desentranhamento e consequente descarte. 
Minoritariamente, há estudiosos que defendem a utilização das provas ilícitas e derivadas tanto contra quanto a favor do réu, baseando-se na efetiva realização da justiça. Ainda que uma prova tenha sido produzida fora dos moldes legais ou constitucionalmente estabelecidos, a justa punição do culpado ou sua correta absolvição, no caso de inocência, seria justificável para a relativização do comando proibitivo constitucional em foco.

O presente artigo objetiva uma reflexão acerca do aproveitamento das provas ilícitas e suas derivadas no processo penal brasileiro, indagando em quais circunstâncias seria admissível o seu aproveitamento.

O assunto discutido é de ímpar importância, pois em jogo está, consequentemente, a restrição da liberdade do indivíduo e seus limites, sendo essencial que este trabalho instigue discussões acadêmicas, questionamentos e novas contribuições ao tema.

\section{MÉTODOS}

Fora desenvolvido o presente artigo a partir de extenso levantamento bibliográfico, sendo baseado no estudo, na leitura e no fichamento de livros, revistas científicas e/ou acadêmicas, jornais, periódicos, artigos, dissertações, teses, textos legislativos e jurisprudência.

Visou-se uma discussão partindo do raciocínio lógico do geral para o particular, fazendo-se uso do método hipotético-dedutivo.

\section{RESULTADOS}

O termo prova é derivado de probatio, em latim, significando exame, verificação, inspeção. Provar, portanto, é o ato pelo qual há a extração da veracidade e autenticidade dos fatos alegados. Prova, por sua vez, é tanto entendida como o meio utilizado para a demonstração de fato controvertido, quanto como o resultado gerado pelo aproveitamento das provas, atestando a autenticidade ou não do fato. (BARBOSA, 2008).

Renato Marcão (2017, p. 437) assevera que:

Em sentido estrito, prova é a informação ou o conjunto de informações determinadas, trazidas aos autos em que materializada a persecução penal, por iniciativa do Delegado de Polícia, das partes no processo, pelo juiz ou por terceiros. Trata-se de uma reconstrução histórica subjetivo-objetiva que tem por escopo demonstrar as razões e a dinâmica do fato passado.

Destarte, a prova possui claro e complicado escopo: a busca pela maior coincidência alcançável da realidade histórica, sendo esta a verdade dos fatos como efetivamente se desenrolaram na realidade. Objetiva-se, portanto, a reconstrução da verdade - tarefa das mais difíceis, isto quando não se mostra impossível. (PACELLI, 2017).

Sobre a tarefa probatória de consecução da verdade real, em sua obra, complementa o nobre autor (2017, p. 333):

\begin{tabular}{|c|}
\hline $\begin{array}{l}\text { ara a consecução de tã } \\
\text { gantesca tarefa, sã } \\
\text { spponibilizados diverso } \\
\text { leios ou métodos d } \\
\text { rova, com os quais ( } \\
\text { lediante os quais) s } \\
\text { spera chegar o mai } \\
\text { róximo possível d } \\
\text { alidade dos fato } \\
\text { vestigados, submetidos } \\
\text { orém, a um limit } \\
\text { reviamente definido n } \\
\text { onstituição Federal: } \\
\text { speito aos direitos e à } \\
\text { arantias individuais, d } \\
\text { cusado e de terceiros } \\
\text { rotegidos pelo imens } \\
\text { lanto }\end{array}$ \\
\hline
\end{tabular}

A convicção do juiz é gerada por meio da apresentação de provas, consubstanciando a persuasão racional. Convence-se o julgador da verdade com a demonstração lógico-racional de vários elementos ao longo da instrução apontados, sendo estes denominados de provas. (NUCCl, 2015).

Ainda, alega Távora e Assumpção (2012, p. 17) que:

A demonstração da "verdade" dos fatos é feita por intermédio da utilização probatória, e a prova é tudo aquilo que 
contribui para a formação do convencimento do magistrado, demonstrando os fatos, atos, ou até mesmo o próprio direito discutido no litígio. Intrínseca no conceito está a sua finalidade, o objetivo, que é a obtenção do convencimento do julgador, decidindo pela condenação ou absolvição do réu por meio da apreciação do manancial probatório carreado aos autos.

Com exceção dos fatos notórios; evidentes; presumidos; incontroversos; e inúteis, todos os fatos alegados precisam ser provados. Percebe-se, portanto, a importância do elemento probatório.

No campo do direito processual penal, a atividade probatória tem acentuada relevância, uma vez que, no processo criminal, busca-se, sobretudo, a consecução da verdade material, real, pois, em jogo está a manutenção ou supressão de um dos principais direitos fundamentais: a liberdade.

Para que o direito fundamental à liberdade de um indivíduo seja restrito, há que se obedecer a normas que garantam que o eventual resultado prisão seja obtido ou não com o máximo de obediência aos princípios e normas do direito processual penal brasileiro.

Segundo Marcão (2017, p. 451):

Decorre evidente do sistema formal adotado que a atividade probatória não pode ser desregrada. Não tem sentido imaginar que qualquer pessoa, a qualquer tempo, possa produzir qualquer tipo de prova nos autos, sem critério algum.

Assim, em respeito ao princípio do contraditório, busca-se prover maior liberdade probatória possível para as partes, numa maior persecução da verdade material. O contraditório e a ampla defesa, considerados no direito moderno como essenciais à prestação do serviço jurisdicional, são verdadeiros balizadores da efetiva realização da justiça concreta.
Entretanto, como afirma Marcão (2017, p. 601), "embora ampla, a iniciativa probatória não é ilimitada".

Ainda, Tourinho Filho (2007, p. 221) aduz que:

Assim, não há, em
princípio, nenhuma
restrição aos meios de
provas, com ressalva,
apenas e tão somente,
daqueles que repugnam a
moralidade ou atentam
contra a dignidade da
pessoa humana. E por que
não são admissíveis? Em
face de limitações
impostas por princípios
constitucionais e até
mesmo de Direito
Material.

Como resultado, há a restrição às provas obtidas em desencontro com princípios do Direito e suas normas, sendo consideradas, assim, ilícitas.

Há grande controvérsia sobre a possibilidade do aproveitamento das provas consideradas ilícitas ou antijurídicas. Em seu artigo 5o, inciso LVI, a Constituição Federal aduz que "são inadmissíveis, no processo, as provas obtidas por meios ilícitos" (BRASIL, 1988).

Não bastasse a proibição constitucional, são também mencionadas no artigo 157 do Código de Processo Penal pátrio: "São inadmissíveis, devendo ser desentranhadas do processo, as provas ilícitas, assim entendidas as obtidas em violação a normas constitucionais ou legais". (BRASIL, 1941).

"Prova ilícita é aquela cuja obtenção viole princípios constitucionais ou que contraria normas de direito material, tais como a confissão mediante tortura e a interceptação telefônica não autorizada judicialmente." (SILVA; FREITAS, 2012, p. 274)

Ensina o eminente jurista Luiz Flávio Gomes (2009) que, conforme a redação do artigo 157 do CPP, provas ilícitas são as obtidas mediante violação a normas constitucionais ou legais. Em outras palavras, prova ilícita caracteriza-se como aquela que viola regra de direito material, no momento de sua obtenção. Com o tema possuindo normas voltadas principalmente aos órgãos persecutórios do Estado, também abrange os particulares, que ficam proibidos de obter provas de maneira 
ilícita. Alguém que invada consultório ou escritório para subtrair provas estaria, assim, obtendo-as de forma ilícita.

Para este autor, tais regras possuem total afinidade com a preservação dos direitos fundamentais da pessoa.

No mesmo sentido, aponta Marcão (2017, p. 602):

São dois, portanto, os fundamentos jurídicos para que se reconheça a ilicitude da prova: 19) violação de normas constitucionais; 20) violação de normas infraconstitucionais.

Haverá prova ilícita por violação de norma constitucional, por exemplo, quando for produzida em desrespeito ao art. 5, $\mathrm{XI}$, da $\mathrm{CF}$, onde se lê que a casa é o asilo inviolável do indivíduo, ninguém nela podendo penetrar sem consentimento do morador, salvo em caso de flagrante delito ou desastre, ou para prestar socorro, ou, durante o dia, por determinação judicial. De igual maneira, dentre outras hipóteses, mácula surgirá se houver ofensa ao disposto no mesmo art. 5o, VII, segundo o qual é inviolável o sigilo da correspondência e das comunicações telegráficas, de dados e das comunicações telefônicas, salvo, no último caso, por ordem judicial, nas hipóteses e na forma que a lei estabelecer para fins de investigação criminal ou instrução processual penal.

Ainda, quanto às provas ilícitas obtidas mediante violação de normas legais, prossegue este doutrinador no sentido de que as provas conduzidas em desconformidade com normas infraconstitucionais também são consideradas ilícitas. É o caso, por exemplo, da confissão obtida mediante tortura; do reconhecimento pessoal realizado em desobediência ao disposto no artigo 226 do CPP; e do laudo pericial realizado por único perito que não seja oficial.

Em oposição às provas ilegítimas que, depois de declaradas nulas, permanecem nos autos, as provas ilícitas devem ser destes desentranhadas, por meio de incidente de ilicitude de prova. (GOMES, 2009).

Quanto ao procedimento de retirada das provas ilícitas do processo, Pacelli (2017, p. 351) menciona:

Nos termos do art. 157, caput, CPP, as provas obtidas ilicitamente deverão ser desentranhadas dos autos, esclarecendo o § 30 do aludido dispositivo legal que a decisão de desentranhamento estará sujeita à preclusão. No entanto, nada se diz acerca do momento processual em que tal ocorrerá. A nosso juízo, deve o juiz apreciar a ilicitude da prova e o seu consequente

desentranhamento dos autos antes da audiência de instrução criminal, ou seja, após a apresentação de defesa escrita, desde que, é claro, a prova tenha sido juntada em momento anterior. Tratando-se de prova apresentada em audiência, deve o juiz, de imediato, apreciar a questão.

Assim, pugna-se por maior legalidade do devido processo legal, legitimando a prestação jurisdicional pelo Poder Judiciário, em obediência aos diversos preceitos constitucionais necessários.

Por outro lado, diferentemente das provas ilícitas propriamente ditas, produzidas de maneira antijurídica, as provas derivadas destas são obtidas de maneira diversa, de acordo com os ditames legais e o due law process.

Contudo, tendem a ser consideradas inválidas e descartadas, pois, apesar de sua obtenção conforme os moldes da legalidade, somente foram alcançadas pela utilização de 
provas ilícitas, sendo aquelas contaminadas pela antijuridicidade destas.

Nessa perspectiva se enquadra a Teoria dos Frutos da Árvore Envenenada, ou fruits of the poisonous tree doctrine. De maneira análoga, se a prova anterior é ilícita (envenenada), as provas subsequentes (frutos), vindas exclusivamente dela também o serão.

A fim de se realizar uma maior proteção das garantias da pessoa humana e ampliar a eficácia dos princípios e normas constitucionalmente estabelecidos, estende-se o rigor conferido às provas ilícitas às suas derivadas, transmitindo-se sua ilicitude, sendo estas igualmente banidas do processo.

Analisadas as provas e suas caracterizações, passa-se à apreciação acerca da aceitação e aplicabilidade destas no processo penal brasileiro, ressaltando-se as correntes e as suas implicações no caso concreto.

A doutrina se divide quanto à admissibilidade das provas antijurídicas e, especialmente, a favor de quais partes, no processo penal, poderiam ser utilizadas. Leva-se em conta, ainda, a relação entre o direito tutelado no processo persecutório e o direito violado na obtenção da evidência ilícita, como forma de regular a utilização ou não destas, em homenagem ao princípio da proporcionalidade.

A prova produzida em juízo objetiva o reconhecimento formal de uma demonstração de verdade, para que, assim, dela possam surgir os efeitos jurídicos na lei previstos. Para tanto, o ambiente processual não pode comportar qualquer tipo de atividade probatória, sem distinção. Como mecanismos de restrição, há comando constitucional (CF, art. 5ㅇ, LVI) e legal (CPP, art. 157) contra as provas ilícitas e as derivadas de provas ilícitas. (MARCÃO, 2017).

Alguns autores entendem que a capacidade probatória não pode se sobressair em detrimento dos direitos e garantias fundamentais, sendo necessário que eventuais violações às normas constitucionais ou legais sejam impedidas de surtir efeito probatório no processo penal.

Sobre a limitação quando da obtenção das provas, aduz Corrêa (2006, p. 14):

Conquanto no processo penal o objetivo da instrução probatória seja a busca da verdade real material ou histórica -, na fase hodierna, de evolução dos direitos e garantias fundamentais e afirmação dos direitos humanos, além da distância temporal entre o ocorrido e a sua reconstituição no processo, aquele objetivo não pode ser perseguido de forma absoluta, estando submetido a limitações e proibições formais e materiais.

Em nome de uma máxima observância às normas reguladoras da atividade probatória, com o escopo de se resguardar os direitos e garantias individuais, consubstancia-se a teoria obstativa das provas ilícitas.

Autoexplicativa, esta teoria defende o impedimento à utilização de provas ilícitas e derivadas de ilícitas no processo penal, tendo como justificativa três vertentes distintas. Seriam inadmissíveis, pois consideradas completamente antijurídicas, atentando contra o universo jurídico considerado como um todo; ou imorais; ou inconstitucionais.

Evidencia-se a função protetora da vedação da utilização das provas ilícitas, consideradas nocivas ao devido processo legal e aos direitos fundamentais. Sua proibição acabaria por garantir legitimidade ao processo, sem que fosse contaminado pela ilicitude pelas quais seriam tais provas produzidas.

Por diferentes fundamentos, a prova ilícita é largamente vedada, considerada inadmissível por parte considerável da esfera jurídica, de modo que para que a restrição do direito fundamental à liberdade de um indivíduo seja legítima, esta deve ser feita pautada em normas que garantam que eventual resultado prisão seja obtido ou não com a máxima observância aos princípios e normas do direito processual vigente.

Entretanto, em casos atípicos e excepcionais, pode haver uma relativização da proibição das provas ilícitas, caso configurem como única maneira de se provar a inocência do acusado, em nome da ampla defesa e da dignidade da pessoa humana do inocente.

Em vista disso, tem-se admitido, por grande parte da doutrina, aproveitamento das provas ilícitas pro reo, porque seu direito fundamental à liberdade estaria protegido, ainda que violasse direitos menos importantes. Sacrifica-se, portanto, bens jurídicos de menor 
consideração, resguardada essa violação pelos princípios constitucionais da presunção da inocência e da ampla defesa.

Ante o exposto, verifica-se que há a aceitação significativa da prova ilícita favor rei, tanto pelo fundamento de ampla defesa, por meio da valoração dos bens em conflito, quanto pela justificativa de caracterização de excludente de ilicitude.

Além da discussão acerca do aproveitamento das provas ilícitas favor rei, há debate acerca da utilização destas pro societate, ou seja, contra o réu, em casos específicos.

É majoritariamente rejeitada pela doutrina, que entende que o Estado, ainda que representando a sociedade, não pode se valer de meios ilícitos durante a persecução criminal do acusado.

Entretanto, parte da doutrina defende que a teoria da proporcionalidade abarca também o seu uso contra o réu, quando em casos de conflitos entre direitos fundamentais de grande relevância.

A fim de analisar se deve ou não utilizarse de provas ilícitas pro societate, o operador do direito deve valer-se de um conjunto de questionamentos, estes também realizados quando do aproveitamento pro reo. (BARBOSA, 2008).

Inicialmente, há que se constatar efetiva colisão entre direitos fundamentais. Verificada, estabelecer-se-á as circunstâncias importantes a serem consideradas. Depois, analisa-se se a restrição de direitos fundamentais atende à finalidade intentada, assim como a apropriação e utilidade das medidas adotadas em face do objetivado.

Ainda, há a necessidade de se considerar se os prejuízos consequentes da medida serão os menores possíveis. A inexistência de meio menos gravoso que não este é imperiosa, uma vez que a restrição de direitos fundamentais do acusado deve ser realizada apenas como ultima ratio. Finalmente, há a ponderação dos bens em conflito, e a certificação de que o meio utilizado é razoavelmente idôneo para a consecução do fim pretendido.

Desta forma, por meio da análise da preponderância de um princípio fundamental sobre outro, e a constatação da necessidade da prova ilícita no caso concreto, a utilização pro societate é aceita por parte da doutrina.

$$
\text { Vale ressaltar que, }
$$

contemporaneamente, há um latente avanço da influência das organizações criminosas, cada vez mais preparadas para desenvolver suas atividades delituosas, favorecendo-se de regras como o princípio da admissibilidade das provas ilícitas para perpetuar seus atos contra a ordem jurídica.

Neste sentido é o posicionamento de Aranha (1994, p. 54):

Em nome de um
exagerado amor ao
dogmatismo, grandes
crimes e poderosos e
perigosos criminosos
podem ficar impunes. Não
devemos esquecer que o
crime organizado é,
quanto à sua execução,
quase perfeito, porque
planejado cientificamente,
o que exige investigações
mais apuradas.

Portanto, há casos em que a restrição de algum direito fundamental possa ser essencial para a consecução da verdade real e a punição do culpado, favorecendo, assim, a sociedade.

Em decisão referente a Habeas Corpus impetrado, o Supremo Tribunal Federal já constatou a valoração entre direitos fundamentais, possibilitando a restrição de um deles em favor da sociedade (BRASIL, 1994, p. 01):

EMENTA: HABEAS CORPUS
- ESTRUTURA FORMAL DA
SENTENÇA E DO ACÓRDÃO
- OBSERVÂNCIA
ALEGAÇÃO
INTERCEPTAÇÃO
CRIMINOSA DE CARTA
MISSIVA REMETIDA POR
SENTENCIADO
UTILIZAÇÃO DE CÓPIAS
XEROGRÁFICAS NASO
AUTENTICADAS
PRETENDIDA ANÁLISE DA
PROVA - PEDIDO
INDEFERIDO. - (...) - A
administração
penitenciária,
fundamento em razões de
segurança pública, de
disciplina prisional ou de
preservação da ordem
jurídica, pode, sempre
excepcionalmente,
desde que respeitada a
norma inscrita no art. 41 ,


parágrafo único, da Lei $n$. 7.210/84, proceder a interceptação da correspondência remetida pelos sentenciados, eis que a cláusula tutelar da inviolabilidade do sigilo epistolar não pode constituir instrumento de salvaguarda de práticas ilícitas. - O reexame da prova produzida no processo penal condenatório não tem lugar na ação sumaríssima de habeas corpus. (HC 70.814-SP. 1a Turma. Rel. Min. Celso de Mello. J. 01/03/1994).

Ressalva-se, entretanto, a necessidade de se pautar em princípios norteadores que balizem a aplicação ou não da teoria da proporcionalidade às provas ilícitas pro societate, por meio da doutrina e da jurisprudência, uma vez que o Estado, em sua função legislativa, normalmente não consegue alcançar a dinâmica da sociedade: cria-se muito mais situações práticas do que as previstas em lei.

Há casos, como o julgamento do $\mathrm{HC}$ 75.338-8/RJ, de relatoria do Ministro Nelson Jobim, onde prova considerada ilícita foi utilizada a favor da acusação (BRASIL, 1998, p. 01):

HABEAS CORPUS. PROVA. LICITUDE. GRAVAÇÃO DE TELEFONEMA POR INTERLOCUTOR. É LÍCITA A GRAVAÇÃO DE CONVERSA TELEFÔNICA FEITA POR UM DOS INTERLOCUTORES, OU COM SUA AUTORIZAÇÃO, SEM CIÊNCIA DO OUTRO, QUANDO HÁ INVESTIDA CRIMINOSA DESTE ÚLTIMO. É

INCONSISTENTE E FERE O SENSO COMUM FALAR-SE EM VIOLAÇÃO DO DIREITO À PRIVACIDADE QUANDO INTERLOCUTOR GRAVA DIÁLOGO COM SEQÜESTRADORES, ESTELIONATÁRIOS OU QUALQUER TIPO DE CHANTAGISTA. ORDEM INDEFERIDA. (HC 75338, Relator(a): Min. NELSON
JOBIM, Tribunal Pleno, julgado em 11/03/1998, DJ 25-09-1998 PP-00011 EMENT VOL-01924-01 PP00069)

Isto posto, vislumbra-se a restrita possibilidade de aproveitamento das provas ilícitas pela acusação, desde que cobertas por rígida análise de ponderação acerca do conflito de direitos fundamentais de cada caso, uma vez que, caso usadas amplamente e sem discriminação, as provas ilícitas contra o réu podem transformar o Estado em verdadeiro gigante processual, afetando o equilíbrio de armas entre o réu e a acusação.

Contudo, é primordial que haja uma valoração da restrição a direito fundamental que se pretende realizar e da realização da justiça que se almeja, para que, só assim, seja justificada a aplicação de provas ilícitas contra o réu.

Caso contrário, sem minuciosos procedimentos de ponderação sobre o correto aproveitamento ou não das provas ilícitas pro societate, o processo penal tornar-se-ia território demasiadamente hostil ao réu, estando, na maioria dos casos, manifestamente despreparado frente a capacidade probatória de um Estado que poderia se valer de meios legalmente inapropriados para maximizar a persecução penal, de maneira não excepcional e, provavelmente, em muitas vezes, imoral.

\section{DISCUSSÃO}

Conforme exposto, doutrina maioritária aponta para uma vedação do uso das provas ilícitas no processo criminal. Em nome de uma maior proteção às garantias do acusado e de um efetivo respeito ao conjunto normativo, restringe-se a capacidade probatória do Estado. Como afirma Marcão (2017), não pode a atividade probatória ser desregrada e sem critério algum.

Por esse ponto de vista, a própria restrição à capacidade probatória seria uma maneira de se garantir a liberdade do acusado, de modo que a punição deste não pode ser perseguida a qualquer custo. Essas limitações e proibições, tanto formais quanto materiais, são, assim, resultado da evolução dos direitos e das garantias fundamentais (CORRÊA, 2006).

Por outro lado, a rejeição de prova considerada ilícita, em caso de produção pela defesa e em se tratando de única e cabal prova 
da inocência do acusado, incita importante questionamento. A justificação, por meio do argumento de ter sido colhida de forma alheia aos moldes legais, acabaria por violar a ampla defesa e o contraditório.

Desta forma, significativa parte $d a$ doutrina aponta para possível aproveitamento de provas ilícitas quando forem usadas pela defesa favor rei - de modo que sua aceitação se basearia no real exercício do contraditório e da ampla defesa.

Conforme afirma Barbosa (2008), é necessário que um conjunto de questionamentos seja feito para que se chegue a conclusão neste sentido, valorando-se diferentes direitos fundamentais e a aplicação de um em detrimento de outro.

Ainda, presente está o questionamento sobre a utilização de provas ilícitas pro societate. Justifica-se, também, pela alegação de ser uma maneira de se concretizar a realização da justiça na condenação de um culpado, especificamente quando inserido num contexto em que as normas figurem como indevida e desproporcional proteção ao réu, representando verdadeiras amarras à investida da sanção estatal tida como justa e, muitas vezes, clamada pela sociedade.

\section{CONSIDERAÇÕES FINAIS}

O Direito Penal e o Direito Processual Penal baseiam-se, ao menos em tese, no Princípio da Dignidade da Pessoa Humana, objetivando a tutela, exercida pelo Estado, do convívio entre indivíduos e seus interesses.

Assim, é celebrada a vedação às provas ilícitas e sua utilização, revestindo-se o procedimento penal de uma alegada maior higidez, dado que a legalidade é absolutamente respeitada.

Contudo, nada no Direito é localizado no âmbito de certo ou errado, de preto ou branco. Pelo contrário, o Direito trata da regulação da chamada área cinzenta, onde um mesmo contexto tem diversos pontos de vista a serem apreciados e valorados.

Deste modo, não raramente, verificam-se situações onde o estrito obedecimento à norma pode significar, no caso concreto, a efetivação de uma injustiça. Esta contradição se dá quando se opta por, rígida e intransitivamente, seguir a letra da lei, ao invés de se primar pela efetivação do objetivo primordial da norma no caso concreto, sendo constatada uma lamentável inversão de valores.
Inobstante, a evolução atual do Direito inflama a importância da discussão acerca da aplicabilidade das provas ilícitas no processo penal pátrio. Julgamentos recentes apontam para uma crescente aceitação de sua utilização pro reo, em homenagem da ampla defesa e da dignidade da pessoa humana. Visa-se, assim, um julgamento mais adequado à verdade real, e não somente a processual.

Para tanto, é necessária a apreciação da questão com uma abordagem diferente: ao invés da rudimentar concepção da Justiça com os olhos vendados, pretende-se uma visão mais realista e adaptada ao caso concreto. A aplicação do Direito em cada caso deve ser aprofundada e humanizada, para que, em cada um deles, a espada, símbolo da força da prestação jurisdicional, seja, verdadeiramente, sinônimo de justiça.

Os autores declaram não haver qualquer potencial conflito de interesse que possa interferir na imparcialidade deste trabalho científico.

\section{REFERÊNCIAS}

ARANHA, A. J. Q. T. C. Da prova no processo penal. 3. ed. São Paulo: Saraiva, 1994.

BARBOSA, D. F. Provas ilícitas no processo penal brasileiro. 2008. 66 f. Trabalho de Conclusão de Curso (Graduação em Direito) - Faculdades Integradas "Antônio Eufrásio de Toledo", Presidente Prudente, 2008.

BRASIL. Presidência da República. Decreto-Lei $\mathbf{n}$. 3.689 , de 03 de outubro de 1941. Código de Processo Penal. Rio de Janeiro, 1941. Disponível em:

http://www.planalto.gov.br/ccivil_03/decretolei/Del3689Compilado.htm. Acesso em: 11 set. 2017.

BRASIL. Constituição (1988). Constituição da República Federativa do Brasil. Brasília: Senado Federal, $1988 . \quad$ Disponível em: http://www.planalto.gov.br/ccivil_03/constituica o/constituicaocompilado.htm. Acesso em: 11 set. 2017.

BRASIL. Supremo Tribunal Federal. HabeasCorpus 70.814. Impetrante: Ulisses Azevedo Soares. Coator: Tribunal de Justiça do Estado de São Paulo. Relator Min. Celso de Mello. Brasília, DF, 01 de março de 1994. Disponível em: 
http://stf.jus.br/portal/jurisprudencia/listarJurisp rudencia.asp?s1=\%28HC\%24\%2ESCLA\%2E+E+708 14\%2ENUME\%2E\%29+OU+\%28HC\%2EACMS\%2E +ADJ2+70814\%2EACMS\%2E\%29\&base=baseAcor daos\&url=http://tinyurl.com/blqv6oo. Acesso em: 19 maio 2018.

BRASIL. Supremo Tribunal Federal. HabeasCorpus n. 75.338. Impetrante: José Mauro Couto de Assis. Coator: Órgão Especial do Tribunal de Justiça do Estado do Rio de Janeiro. Relator: Min. NELSON JOBIM. Brasília, DF, 11 de março de 1998. Disponível em: http://redir.stf.jus.br/paginadorpub/paginador.js $p$ ?docTP=AC\&docID=75912. Acesso em 23 jul. 2018.

CORRÊA, S. L. A prova processual penal ilícita e a teoria da proporcionalidade. 2006. $100 \mathrm{f}$. Dissertação (Mestrado em Ciências Jurídicas) Universidade Federal do Paraná, Curitiba, 2006.

GOMES, L. F. Provas ilícitas e ilegítimas: distinções fundamentais. São Paulo: LFG, 2009. Disponível em: https://lfg.jusbrasil.com.br/noticias/1972597/pro vas-ilicitas-e-ilegitimas-distincoes-fundamentais. Acesso em 06 mar. 2018.
MARCÃO, R. Curso de processo penal. 3 ed. São Paulo: Saraiva, 2017. Disponível em: https://integrada.minhabiblioteca.com.br/\#/boo ks/9788547218751/cfi/604!/4/4@0.00:15.3.

Acesso em: 13 set. 2017.

NUCCI, G. S. Provas no processo penal. 4. ed. Rio de Janeiro: Forense, 2015. Disponível em: https://integrada.minhabiblioteca.com.br/\#/boo ks/978-85-309-6304-0/cfi/6/18!/4/526/4@0:100. Acesso em: 20 set. 2017.

PACELLI, E. Curso de processo penal. 21. ed. São Paulo: Atlas, 2017. Disponível em: https://integrada.minhabiblioteca.com.br/\#/boo ks/9788597010268/cfi/6/10!/4/18@0:88.1.

Acesso em: 18 set. 2017.

SILVA, M. A. M.; FREITAS, J. W. Código de processo penal comentado. São Paulo: Saraiva, 2012.

TÁVORA, N.; ASSUMPÇÃO, V. Processo penal II: provas - questões e processos incidentes. São Paulo: Saraiva, 2012.

TOURINHO FILHO, F. C.Processo penal. 29. ed. São $\quad$ Paulo: Saraiva, 2007. 